\title{
Effectiveness of Gloves and Infection Control in Dentistry: Student and Provider Perspectives
}

\author{
Preetha P. Kanjirath, B.D.S., M.D.S., M.S.; Amy E. Coplen, R.D.H.; Jody C. Chapman, B.S.; \\ Mathilde C. Peters, D.M.D., Ph.D.; Marita Rohr Inglehart, Dr. phil. habil. \\ Abstract: The objectives of this study were to explore dental and dental hygiene students', graduate students', and dental pro- \\ fessionals' preferences for certain types of gloves and the reasons for these preferences (Aim 1), as well as determining their \\ knowledge, attitudes, and behavior concerning the use of dental gloves as a means of barrier protection (Aim 2). Data were \\ collected from 198 dental and forty-six dental hygiene students, thirty-five graduate students, and seventy-nine dental profes- \\ sionals (twenty-eight dentists and fifty-one dental hygienists in private practice). The subjects responded to a self-administered \\ anonymous survey. Professionals (dentists: 96.4 percent and dental hygienists: 92.2 percent) were found to be more likely to \\ have a preference for certain types of gloves than students (dental students: 79.2 percent and dental hygiene students: 76 percent) \\ and graduate students (77.1 percent; $\mathrm{p}=.033$ ). "Comfort" was most frequently reported as a reason for glove preference. Large \\ percentages of respondents wrongly believed that gloves provide full protection (students: 50.8 percent; graduate students: 25.7 \\ percent; professionals: 30.4 percent), thought that gloves provide protection as long as there is no visible tear (students: 39.7 \\ percent; graduate students: 28.6 percent; professionals: 18.2 percent), and reported that they would not change gloves during an \\ uninterrupted three-hour long procedure (students: 32.2 percent; graduate students: 23.5 percent; professionals: 22.7 percent). \\ These findings should alert dental educators about the importance of educating their students as well as practicing professionals \\ clearly and comprehensively about infection control and the science and rationale supporting recommended guidelines.
}

Dr. Kanjirath is Clinical Assistant Professor, Department of Periodontics and Oral Medicine, School of Dentistry, University of Michigan; Ms. Coplen is a dental hygienist and a graduate student in the dental hygiene program, School of Dentistry, University of Michigan; Ms. Chapman is a predoctoral dental student, School of Dentistry, University of Michigan; Dr. Peters is Professor of Dentistry, Department of Cariology and Restorative Dentistry, School of Dentistry, University of Michigan; and Dr. Inglehart is Associate Professor of Dentistry, Department of Periodontics and Oral Medicine, School of Dentistry, and Adjunct Associate Professor of Psychology, Department of Psychology, College of Literature, Science, and Arts, University of Michigan. Direct correspondence and requests for reprints to Dr. Marita Rohr Inglehart, Department of Periodontics and Oral Medicine, School of Dentistry, University of Michigan, 1011 North University Avenue, Ann Arbor, MI 48109-1078; 734-763-8073 phone; 734-7635503 fax; mri@umich.edu.

This research was supported with funds for Amy E. Coplen from the NIH/NIDCR T32 Training Grant DE007057 given to the University of Michigan School of Dentistry (PI: Peters).

Key words: infectious diseases, infection control, dental students, dental hygiene students, health care practices, professional behavior, dental education, dental hygiene education, gloves

Submitted for publication 10/9/08; accepted 1/30/09

$\mathrm{H}$ ealth care workers in general are susceptible to contracting infectious diseases while providing patient care if they do not use proper infection control. Dental care providers in particular are at an increased risk as they provide care working with sharp instruments at very high speeds and limited access in an environment that is bathed in saliva and, in many instances, blood. In the late 1970s, several reports found that dentists were three times more likely than the general population to contract hepatitis B. ${ }^{1-4}$ Such reports of the transmission of hepatitis B infection between dentists and patients prompted the American Dental Association (ADA) to develop strict infection control guidelines. ${ }^{4,5}$ With the emergence of the AIDS epidemic in the 1980s, even more stringent precautions became necessary to effectively protect health care workers and the public, leading to the recommendations by the Centers for Disease Control concerning the prevention of HIV transmission in health care settings and universal precautions guidelines. ${ }^{6}$ These recommendations primarily addressed the risk of transmission through 
bloodborne pathogens and were based on the concept that blood or body fluids infected with blood could be contaminated. As a consequence of these efforts and the resulting heightened awareness concerning the transmission of infectious diseases and the importance of infection control, a national survey reported in 1989 a significant increase in the utilization of gloves and other barrier techniques in dental practices. ${ }^{4}$ However, the limitations of universal precautions were recognized subsequently and, in 1996, the Centers for Disease Control adopted the term "standard precautions" to embrace a broader concept of the prevention and transmission of infections. ${ }^{7}$ The objective of these guidelines was to ensure that health care workers are protected from any pathogen in blood or other body fluids from nonintact skin and mucous membranes. One of the cornerstones of the practice of standard precautions is the use of personal protection equipment as barrier controls to prevent skin and mucous membrane exposures; this resulted in the widespread use of latex gloves in dental practices. This increased use of latex gloves, however, resulted in the rise of latex-associated adverse reactions. ${ }^{8}$ Other materials such as vinyl and more recently nitrile have since been introduced as a way to avoid latex-related allergic reactions.

Dental gloves are worn to protect dental care providers from contamination while being in contact with mucous membranes, blood, and saliva. They also protect patients from being infected with any pathogens by the providers. Nonsurgical gloves used in dental practices are single-use, disposable gloves that should be discarded after use. However, there is a wide variation in the properties of gloves made from different materials and by different manufacturers. Research studies found, for example, that the performance of vinyl gloves was significantly inferior to that of latex and nitrile gloves in terms of barrier protection, ${ }^{9-11}$ durability, ${ }^{12}$ and resistance to tear. ${ }^{13,14}$ Nitrile gloves have been found to be comparable to latex gloves in barrier protection, ${ }^{11}$ puncture resistance, ${ }^{14}$ and durability. ${ }^{15}$ However, nitrile gloves have less elasticity, ${ }^{11,15}$ resulting in reduced dexterity for fine motor skills as compared to latex gloves. ${ }^{15}$ This reduced elasticity may cause more fatigue in providers' hands when they use these gloves for long periods of time. ${ }^{16}$

The U.S. Food and Drug Administration (FDA) Center for Devices and Radiological Health is responsible for regulating gloves, ${ }^{17}$ and all medical gloves are required to meet certain acceptable quality levels. However, even intact gloves may fail. Research has found that prolonged use of gloves and the use of products like disinfectants, composite resins, and alcohol may increase the permeability of these gloves. ${ }^{18-20}$ In addition, several studies have found that operators were frequently unaware of the fact that gloves were torn or punctured during use. ${ }^{21-23}$ The use of gloves does not replace hand-washing, and it is recommended to wash hands in between patient care. ${ }^{24}$ There is also an increased risk of contamination of hands during the removal of gloves. ${ }^{24,25}$ Wet hands facilitate the rapid multiplication of bacteria under the gloves. Thorough drying of the hands before putting on gloves is therefore recommended. ${ }^{7}$ However, there is no published guideline to choose gloves based on the type of material of manufacture. Provider preference for any particular type of glove might therefore be determined by factors such as allergies, comfort, dexterity, and cost. Although glove type and the length and type of procedure ${ }^{21,26-28}$ have been shown to have an effect on the integrity of gloves, one could potentially find that this fact might not be taken into consideration in routine practice.

In addition, the practice of double gloving to prevent penetration of pathogens has not been clearly established despite the fact that there is evidence that a lower frequency of inner glove perforations is associated with double gloving. ${ }^{29,30}$ While research found that double gloving did not affect manual dexterity significantly, ${ }^{31,32}$ most practitioners do not adapt this practice because of concerns about a loss of fine motor movements, comfort, or cost. ${ }^{32}$

Although there is a high degree of compliance in adopting standard precautions in dental practices, there is no research that has explored the degree to which health care providers understand the actual effectiveness and nature of protection that gloves provide, nor are there studies that assessed dental health care providers' perceptions, attitudes, and behavior concerning the use of gloves as barrier protection. Currently, there are neither clear guidelines to help choose a type of glove for certain procedures nor easily accessible information about the factors that affect these decisions. Health care personnel might therefore arbitrarily choose a certain type of dental glove based on their perceptions of comfort or the availability of gloves in a dental office. This situation should raise concerns because it is of utmost importance that health care workers make educated decisions about the type of gloves they use based on the tasks they perform and the level of risk involved. 
The various types of gloves are not equal in the way they perform, ${ }^{9-18}$ and all procedures do not require the same level of protection. ${ }^{19-23}$ All dental health care providers should be educated and made aware of the science that drives the guidelines and policies concerning preventive and postexposure procedures in the workplace. With new and emerging infections and mutating and resistant microorganisms, the question arises whether graduating dentists and dental hygienists are adequately prepared for making the right decisions concerning infection control.

This survey therefore explored dental and dental hygiene students', graduate students', and dental professionals' preferences for certain types of gloves and the reasons for these preferences (Aim 1), as well as determining their knowledge, attitudes, and behavior concerning the use of dental gloves as a means of barrier protection (Aim 2).

\section{Methods}

This study was approved by the Institutional Review Board (IRB) for the Health Sciences at the University of Michigan (\# HUM00010524).

Data were collected from three groups of respondents. Group 1 included 198 second- $(\mathrm{N}=65)$, third- $(\mathrm{N}=75)$, and fourth-year $(\mathrm{N}=58)$ dental students and forty-six third- $(\mathrm{N}=25)$ and fourth-year $(\mathrm{N}=21)$ dental hygiene students from the University of Michigan School of Dentistry. First-year dental students and first- and second-year dental hygiene students were not included in the sample because these students lack clinical experiences. While all dental hygiene students were female, 52.5 percent of the responding dental students were male. Each dental student class consisted of approximately 100 students and each dental hygiene class of approximately thirty students. However, only the students attending certain lectures were asked to participate, bringing the response rates to well over 50 percent for each group of students. Group 2 consisted of thirty-five graduate dental students (37.1 percent male and 62.9 percent female) from the University of Michigan. The third group included dental health care professionals (twenty male and eight female dentists and fifty-one female dental hygienists) attending a continuing education (CE) course or a local professional society meeting in Ann Arbor, Michigan. No data are available concerning the response rates of the graduate students, dentists, and dental hygienists because the researchers were not present when the surveys were distributed by the CE instructors. The majority of the dentists had practiced their profession for more than ten years ( 80 percent), with only 12 percent practicing under five years and 8 percent between five and ten years, while more dental hygienists had been practicing for shorter periods of time (under five years: 26.3 percent; five to ten years: 18.4 percent; over ten years: 55.3 percent).

Data were collected using a self-administered anonymous survey. All respondents were informed about the study at either the beginning or end of a regularly scheduled class or CE program/meeting and asked to volunteer to respond. Consent forms and surveys were distributed to all students in the classes and to all professionals at the $\mathrm{CE}$ classes or professional local meetings to ensure anonymity. Students were explicitly informed that the decision not to respond would have no effect on their grades. Responding to the survey took approximately five minutes.

The survey was developed based on a previous survey with dental and dental hygiene students. This earlier survey explored infection control considerations when treating patients infected with the herpes simplex virus $1 .{ }^{33}$ The revised survey retained the questions concerning the respondents' background characteristics, such as whether the respondents were students, graduate students, dental hygienists, or dentists as well as their gender. In addition, it retained the questions under the heading "Practical approach to avoid contamination and cross-infections," which included questions about the respondents' professional beliefs, attitudes, and behavior when treating patients with communicable, infectious diseases. However, new questions were added concerning the respondents' preferences for certain types of dental gloves and the reasons for these preferences as well as the respondents' thoughts and knowledge about the protective effects of dental gloves. This revised survey was piloted with a small group of experts representing the respondent groups (two dentists, one dental hygienist, one dental student, and one behavioral scientist), who gave feedback concerning the face validity of this survey.

The data were analyzed using SPSS (Version 16.0, Student Version for Windows, Prentice Hall, 2008). Frequency distributions are provided to describe the findings, and chi-square tests were used to determine whether there were significant differences between the frequencies of answers that the various groups of respondents gave. 


\section{Results}

The first objective was to assess dental and dental hygiene students', graduate students', and dental professionals' preferences for certain types of gloves and the reasons for those preferences. Table 1 shows that the five groups differed significantly in the frequencies with which they preferred to wear a certain type of glove. When respondents were asked "Do you prefer to wear a certain type of glove?," 96.4 percent of the dentists and 92.2 percent of the dental hygienists responded that they had a clear preference. While the three student groups had relatively lower levels of preferences (dental students: 79.2 percent; dental hygiene students: 76 percent; graduate students: 77.1 percent; $\mathrm{p}=.033$ ), the majorities in each group of students still reported to have a glove preference.

A follow-up question inquired why the respondents had preferences. Table 2 shows that, for all groups of respondents, "comfort" was the most frequently named reason why they preferred a certain type of glove (students: 65.7 percent; graduate students: 62.9 percent; professionals: 77.2 percent; $\mathrm{p}=.129$ ) and "cost" the least frequently named consideration (students: 5.7 percent; graduate students: 5.7 percent; professionals: 8.9 percent; $p=.601$ ). While similar percentages of respondents in each group indicated that "patient allergies" were a reason for their glove preference (students: 23.7 percent; graduate students: 20 percent; professionals: 25.3 percent;

\begin{tabular}{|c|c|c|c|}
\hline Students & Years 2 and 3 & Year 4† & Total‡ \\
\hline Dental & $74.1 \%$ & $91.4 \%$ & $79.2 \%$ \\
\hline Dental hygiene & $76.0 \%$ & $76.2 \%$ & $76.0 \%$ \\
\hline Graduate & $77.1 \%$ & - & $77.1 \%$ \\
\hline Professionals & $\begin{array}{l}<10 \text { Years } \\
\text { of Practice }\end{array}$ & $\begin{array}{l}\geq 10 \text { Years } \\
\text { of Practice }\end{array}$ & Total \\
\hline Dentists & $100 \%$ & $95.0 \%$ & $96.4 \%$ \\
\hline Dental hygienists & $88.2 \%$ & $95.5 \%$ & $92.2 \%$ \\
\hline \multicolumn{4}{|c|}{$\begin{array}{l}\text { †The percentages of "yes" vs. "no" responses of the dental } \\
\text { versus dental hygiene students in Year } 4 \text { had a tendency to } \\
\text { differ (chi-square test: d.f.=1; } p=.083 \text { ). } \\
\text { †The percentages of "yes" vs. "no" responses of the five } \\
\text { groups of respondents differed significantly (chi-square } \\
\text { test: } d . f .=4 ; p=.033 \text { ). }\end{array}$} \\
\hline
\end{tabular}

$\mathrm{p}=.827$ ), the three respondent groups differed in the degree to which concerns about "protection" and "provider allergies" affected their preferences. Significantly higher percentages of professionals and graduate students named these two reasons compared to students (students: 21.2 percent and 17.1 percent; graduate students: 37.1 percent and 25.7 percent; professionals: 40.5 percent and 38 percent; $p<.001$ for both).

The second objective was to explore the respondents' beliefs/knowledge and their professional attitudes and behaviors concerning the use of dental gloves. Table 3 shows that large percentages of respondents in all three groups either did not know the answer to the question "Do different gloves provide the same protection?" (students: 31.7 percent; graduate students: 23.5 percent; professionals: 18.4 percent) or answered incorrectly with "yes" (students: 48.3 percent; graduate students: 41.2 percent; professionals: 48.7 percent). Only 20 percent of students, 35.3 percent of graduate students, and 32.9 percent of professionals answered correctly that not all types of gloves provide the same protection. However, even these respondents did not correctly answer the followup question about which type of glove provides the best protection. These responses showed that only a small percentage of respondents in each group knew correctly that different types of gloves provide different levels of protection and which type of glove provides the best protection.

This high percentage of incorrect answers also was found when analyzing the responses to the next question: "To what degree do gloves prohibit passage of bacteria and viruses through the glove material?" Large percentages of respondents in all groups wrongly believed that gloves provide full protection (students: 50.8 percent; graduate students: 25.7 percent; professionals: 30.4 percent) or that they prohibit bacteria but not viruses or that they gave little to no protection.

One aspect of being knowledgeable about the way gloves protect health care workers against the transmission of disease is concerned with the length of time these devices provide protection. About a third of the respondents in each group reported that they did not know how long gloves protected them (students: 31 percent; graduate students: 31.4 percent; professionals: 32.5 percent), and quite substantial percentages of respondents believed that gloves protect them as long as there is no visible tear (students: 39.7 percent; graduate students: 28.6 percent; professionals: 18.2 percent). Even respondents who chose 
Table 2. Reasons for preferring certain types of gloves, by percentage of total respondents in each category

\begin{tabular}{|c|c|c|c|c|}
\hline Reasons & Students & Graduate Students & Professionals & $\mathrm{p}$ \\
\hline No preference & $21.6 \%$ & $22.9 \%$ & $6.3 \%$ & .007 \\
\hline Comfort & $65.7 \%$ & $62.9 \%$ & $77.2 \%$ & .129 \\
\hline Protection & $21.2 \%$ & $37.1 \%$ & $40.5 \%$ & .001 \\
\hline Provider allergies & $17.1 \%$ & $25.7 \%$ & $38.0 \%$ & .001 \\
\hline Patient allergies & $23.7 \%$ & $20.0 \%$ & $25.3 \%$ & .827 \\
\hline Cost & $5.7 \%$ & $5.7 \%$ & $8.9 \%$ & .601 \\
\hline
\end{tabular}

Note: The percentages add up to more than $100 \%$ because the respondents could choose more than one reason.

Table 3. Beliefs concerning the way gloves protect the provider, by percentage of total respondents in each category

\begin{tabular}{|c|c|c|c|c|}
\hline Questions & Students & Graduate Students & Professionals & $\mathrm{p}$ \\
\hline \multicolumn{5}{|l|}{ Do different gloves provide the same protection? } \\
\hline I don't know & $31.7 \%$ & $23.5 \%$ & $18.4 \%$ & .04 \\
\hline Yes & $48.3 \%$ & $41.2 \%$ & $48.7 \%$ & \\
\hline No & $20.0 \%$ & $35.3 \%$ & $32.9 \%$ & \\
\hline \multicolumn{5}{|l|}{ If no, best protection by } \\
\hline Vinyl & $19.4 \%$ & $33.3 \%$ & $8.3 \%$ & .001 \\
\hline Latex & $27.8 \%$ & $50.0 \%$ & $33.3 \%$ & \\
\hline Nitrile & $50.0 \%$ & $16.7 \%$ & $58.3 \%$ & \\
\hline No answer & $2.8 \%$ & - & - & \\
\hline \multicolumn{5}{|c|}{$\begin{array}{l}\text { To what degree do gloves prohibit passage of bacteria } \\
\text { and viruses through the glove material? }\end{array}$} \\
\hline Full prohibition & $50.8 \%$ & $25.7 \%$ & $30.4 \%$ & $<.001$ \\
\hline Protection against most bacteria and viruses & $21.8 \%$ & $31.4 \%$ & $41.8 \%$ & \\
\hline Prohibit bacteria, but not viruses & $2.1 \%$ & $11.4 \%$ & $1.3 \%$ & \\
\hline Little to no protection & $.8 \%$ & $2.9 \%$ & $3.8 \%$ & \\
\hline I don't know & $24.4 \%$ & $28.6 \%$ & $22.8 \%$ & \\
\hline \multicolumn{5}{|l|}{ How long do gloves provide adequate protection? } \\
\hline As long as no visible tear & $39.7 \%$ & $28.6 \%$ & $18.2 \%$ & .029 \\
\hline 0 to 30 minutes & $10.7 \%$ & $14.3 \%$ & $14.3 \%$ & \\
\hline 30 minutes to 1 hour & $12.0 \%$ & $14.3 \%$ & $24.7 \%$ & \\
\hline 1 to 2 hours & $4.1 \%$ & $11.4 \%$ & $7.8 \%$ & \\
\hline 2 or more hours & $2.5 \%$ & - & $2.6 \%$ & \\
\hline I don't know & $31.0 \%$ & $31.4 \%$ & $32.5 \%$ & \\
\hline
\end{tabular}

Note: Percentages in some categories do not total 100\% because of rounding.

a certain length of time showed ignorance to some degree because they did not indicate that the length of time depends on the type of glove and the procedure performed. Given these answers, it is, however, not surprising that the follow-up question- "If you were involved in an uninterrupted three-hour procedure, how often would you change gloves?"- - resulted in an equally wide range of responses, with large percentages indicating "never," "after one hour," and "after 30 minutes" (see Table 4).

In addition to asking general questions, two specific questions inquired about the respondents' behavior when approaching to treat a patient a) with an active cold sore or b) with a healing cold sore. Responses to these questions should consider that patients with trauma or emergency treatment needs might require immediate care, while dental care providers should postpone routine care of patients with cold sores. The majority of students and graduate students answered that they would defer treatment when encountering a patient with an active cold sore, while only 29.8 percent of the professionals gave this response. However, 11.5 percent of the students, 9.1 percent of the graduate students, and 14 percent of 


\begin{tabular}{|c|c|c|c|c|}
\hline $\begin{array}{l}\text { If you were involved in an uninterrupted three-hour } \\
\text { procedure, how often would you change gloves? }\end{array}$ & Students & Graduate Students & Professionals & $\mathrm{p}$ \\
\hline \multicolumn{5}{|l|}{ I would change: } \\
\hline After 30 minutes & $28.8 \%$ & $35.3 \%$ & $29.3 \%$ & .117 \\
\hline After 1 hour & $32.6 \%$ & $29.4 \%$ & $36.0 \%$ & \\
\hline After 2 hours & $3.4 \%$ & $11.8 \%$ & $4.0 \%$ & \\
\hline Never & $32.2 \%$ & $23.5 \%$ & $22.7 \%$ & \\
\hline
\end{tabular}

How do you approach treating a patient with an active cold sore?

\begin{tabular}{|c|c|c|c|c|}
\hline Proceed with increased precaution: & $26.9 \%$ & $27.3 \%$ & $29.8 \%$ & .002 \\
\hline Double gloving & $19.0 \%$ & $9.4 \%$ & $17.9 \%$ & \\
\hline Change gloves more often & $5.0 \%$ & $3.1 \%$ & $1.8 \%$ & \\
\hline Wash hands more often & $2.5 \%$ & - & $5.3 \%$ & \\
\hline Proceed with treatment as usual & $11.5 \%$ & $9.1 \%$ & $14.0 \%$ & \\
\hline Inform patient and let patient decide whether to proceed & $5.8 \%$ & $3.0 \%$ & $22.8 \%$ & \\
\hline Defer treatment & $54.3 \%$ & $57.6 \%$ & $29.8 \%$ & \\
\hline
\end{tabular}

\section{How do you approach treating a patient with a healing cold sore?}

\begin{tabular}{lccc}
\hline Proceed with increased precaution: & $22.9 \%$ & $34.3 \%$ & $23.1 \%$ \\
Double gloving & $9.8 \%$ & $15.6 \%$ & $11.9 \%$ \\
Change gloves more often & $3.8 \%$ & $12.5 \%$ & $3.3 \%$ \\
Wash hands more often & $2.4 \%$ & $9.7 \%$ & $3.3 \%$ \\
Proceed with treatment as usual & $50.2 \%$ & $28.6 \%$ & $38.5 \%$ \\
Inform patient and let patient decide whether to proceed & $9.0 \%$ & $17.1 \%$ & $21.5 \%$ \\
Defer treatment & $16.1 \%$ & $17.1 \%$ & $12.3 \%$
\end{tabular}

Note: Percentages in some categories do not total $100 \%$ because of rounding or skipped questions.

the professionals answered that they would proceed with the treatment as usual. In both situations, very low percentages of those respondents who indicated that they would proceed with increased precaution answered that they would double glove, change their gloves more often, or wash their hands more often.

\section{Discussion}

The data convincingly showed that the absolute majority of professionals ( 96.4 percent of the dentists and 92.2 percent of the dental hygienists) had a clear preference for a certain type of glove (see Table 1) and that significantly higher percentages of professionals compared to students had such preferences $(p=.033)$. Concerning the percentages of preferences of different groups of students, it was interesting to find that senior dental students were more likely to have a glove preference (91.4 percent) compared to second- or third-year undergraduate dental students
(74.1 percent), while the percentages of dental hygiene students with glove preferences did not change over time (second- and third-year: 76 percent vs. fourth-year: 76.2 percent). One possible explanation for this differential finding could be that, over the course of the four-year dental curriculum, dental students progress to perform increasingly more complicated dental procedures that require more fine motor skills. As the demands on fine motor skills advance, the dental students might develop a better sense of which type of gloves will allow them to best perform these procedures.

In addition, only 77.1 percent of the graduate students had a preference for a certain type of dental glove. This finding might be related to the fact that the graduate dental students at the University of Michigan not only come from many different dental schools in the United States, but that many finished their undergraduate dental education in countries all over the world. It is possible that this wide variety of 
educational experiences might have affected glove preferences.

Unfortunately, the survey did not include a question concerning which glove the respondents preferred if they indicated that they had a dental glove preference. However, as can be seen in Table 2, the respondents did indicate why they preferred certain gloves. The fact that 65.7 percent of the students, 62.9 percent of the graduate students, and 77.2 percent of the professionals named "comfort" most frequently as their reason for preferring a certain type of glove is worth noting, because one might expect that infection control-related reasons would dominate the respondents' preferences. The percentages of respondents who considered that "protection" was a reason for them to prefer a certain type of glove were relatively smaller and differed among the three groups, with a significantly lower percentage of students $(21.2$ percent) indicating this reason compared to graduate students (37.1 percent) and professionals (40.5 percent). Provider and patient allergies were also reasons quite frequently named, while the cost of gloves was not a consideration for most of the respondents.

One reason why relatively lower percentages of respondents chose "protection" as a reason for their glove preference could be that substantial percentages of respondents wrongly assumed that all gloves provide the same protection (students: 48.3 percent; graduate students: 41.2 percent; professionals: 48.7 percent). However, more than half of the respondents in each group indicated that they either were not sure whether all gloves protect providers to the same degree or believed that different gloves provided various levels of protection (see Table 3 ).

If the respondents thought that different types of gloves provided different levels of protection, they were asked whether gloves made of vinyl, latex, or nitrile provided better protection. Again, a lack of knowledge was found because respondents in all three groups named each of the three types of gloves as providing better protection than other types of gloves. Although it is clearly evident in the literature that vinyl gloves consistently provide inferior quality barrier control compared to the other types of gloves, ${ }^{9-12,15} 19.4$ percent of students, 33.3 percent of graduate students, and 8.3 percent of the professionals who responded "yes" to believing that gloves provided varying degrees of protection stated that they believed vinyl gloves provided the best protection. While nitrile and latex gloves are mostly comparable, ${ }^{12,15}$ nitrile gloves have the added advantage of not leading potentially to an adverse allergic reaction in the provider or the patient. ${ }^{8}$ However, their elasticity might result in reduced dexterity when fine motor skills are required and may cause fatigue in providers who use these gloves for long periods of time. ${ }^{13,15,16}$

Consistent with the range of answers to the question concerning the overall level of protection of dental gloves were the answers to a follow-up question concerning the degree to which gloves prohibit the passage of bacteria and viruses through their material. Again, the three groups of respondents differed significantly in the degrees to which they believed/ knew that gloves prohibit the passage of viruses and bacteria. While 50.8 percent of the students believed that gloves provide complete protection, only 25.7 percent of the graduate students and 30.4 percent of the professionals answered in this fashion. These percentages showed that the more experienced providers actually were better informed overall, because research has found that the integrity of gloves was compromised with use and that there was penetration of virus and bacteria. . $^{10,27,34}$ However, it should raise serious concerns that substantial percentages of students (24.4 percent), graduate students (28.6 percent), and professionals (22.8 percent) indicated that they did not know the extent to which their gloves protected them.

In addition to inquiring about the degree to which respondents felt they were protected by their gloves, it was also interesting to assess how long the respondents believed they were protected by one pair of gloves. The literature consistently supports the evidence that glove type, length of time, and type of procedure impact the quality of barrier protection of the gloves. ${ }^{21-23,27}$ Again, it is noteworthy that substantial percentages of students ( 31 percent), graduate students (31.4 percent), and professionals (32.5 percent) answered "I don't know" to this question, and that the rest of the respondents differed widely in their thoughts concerning the amount of time their gloves would protect them. These answers should raise serious concerns about the providers' understanding of infection control and specifically of how to protect themselves and their patients from the transmission of communicable infectious diseases.

While this question assessed the providers' beliefs/knowledge, the question concerning how often they would change their gloves during an uninterrupted three-hour procedure addressed their own behavior. Based on the same considerations concerning the loss of integrity of the gloves, ${ }^{21-23,27}$ the answers should definitely not include responses indi- 
cating that the providers would not change the gloves at all during a three-hour procedure, nor should the respondents actually wear gloves for more than one and more than two hours. However, substantial percentages of respondents in each group indicated that they actually either never changed their gloves during such a procedure (students: 32.2 percent; graduate students: 23.5 percent; professionals: 22.7 percent) or only after one or two hours (students: 36 percent; graduate students: 41.2 percent; professionals: 40 percent). The respondents who would either never change their protective gloves during an uninterrupted three-hour procedure or who would only change them after one or two hours into the procedure could be putting themselves and their patients at risk for the transmission of communicable infectious diseases. It is interesting to note that there was a significant correlation between the beliefs/knowledge concerning how long gloves protect from infections and the actual behavior concerning the frequencies of changing gloves $(\mathrm{r}=.238 ; \mathrm{p}<.001)$. This finding showed that beliefs/knowledge and behavior were related.

In addition to asking general questions about infection control and the effectiveness of dental gloves, more specific questions were included concerning the use of gloves when treating patients with a very common infectious disease-namely, infections with the herpes simplex virus. These infections are widespread, with the lifetime prevalence of recurrent herpes labialis in the United States being estimated to be between 20 and 45 percent of the adult population, with approximately 100 million episodes occurring annually in immunocompetent individuals. ${ }^{35,36}$ The question therefore is whether the respondents were aware of how to protect themselves and their patients from the transmission of this particular virus. When a patient with an active cold sore presents in a dental clinic, the recommended professional response is to educate the patient about the infection and defer treatment unless it is an acute emergency. ${ }^{33}$ However, not all respondents chose this correct response. Indeed, only 29.8 percent of professionals answered in this fashion, with somewhat higher percentages of students and graduate students answering correctly. This finding that fewer dentists and dental hygienists answered that they would defer treatment could be related to the fact that the provider may already be positive for the disease and also the fact that recurrent herpetic lesions are mostly mild and not debilitating. Hence, the providers might feel comfortable in going ahead with the treatment. However, one would hope that these providers would use all means of protection when providing care for patients with infections that they perceive as more severe such as HIV infections or tuberculosis. In any case, treating a patient with an active cold sore may increase the severity of the episode for the patient. A significant percentage of respondents answered that they would proceed with the treatment of a patient with an active cold sore, but would use increased caution like double gloving. Although the literature supports the belief that double gloving is more effective than using a single pair of gloves, ${ }^{29-32}$ it is important to consider that this practice should then be followed for all patients indiscriminantly. It is also noteworthy that only a small percentage of respondents indicated washing hands as an added precautionary measure. Considering that research has found that washing hands in between changing gloves and more frequently significantly reduces microbial contamination, ${ }^{24,25}$ this lack of affirmative responses should alert educators to the fact that their students might not be aware of this fact.

A follow-up question asked the respondents to explain what they would do if their patient presented with a healing cold sore. It is important to understand that even in this stage of the disease the patients are still shedding viruses and infections are possible, although the risk is reduced. ${ }^{33}$ The wide range of responses to this question again showed that students and professionals alike might lack a clear understanding of this fact and that high percentages of these providers might thus ultimately put themselves and their patients at risk.

Summarizing the results of this study, these findings indicate a lack of understanding of the basics of infection control and the prevention of transmission of communicable infectious diseases not only in large percentages of dental and dental hygiene students, but also in graduate students and among the dentists and dental hygienists who responded to this survey. A useful follow-up study would be to assess dental and dental hygiene educators' awareness, skills, and knowledge about infection control. Figure 1 puts these considerations into the context of a humanistic approach to professional education. . $^{33,37}$ This model postulates that both awareness and skills are needed to develop commitment in dental and dental hygiene educators. In addition, the model predicts that true expertise will result as a consequence of having the skills related to infection control and being knowledgeable. An in-depth understanding of these issues will result only if educators are aware of their significance and are knowledgeable at the same time. The more aware, skilled, and knowledgeable 
INSTRUCTORS

STUDENTS

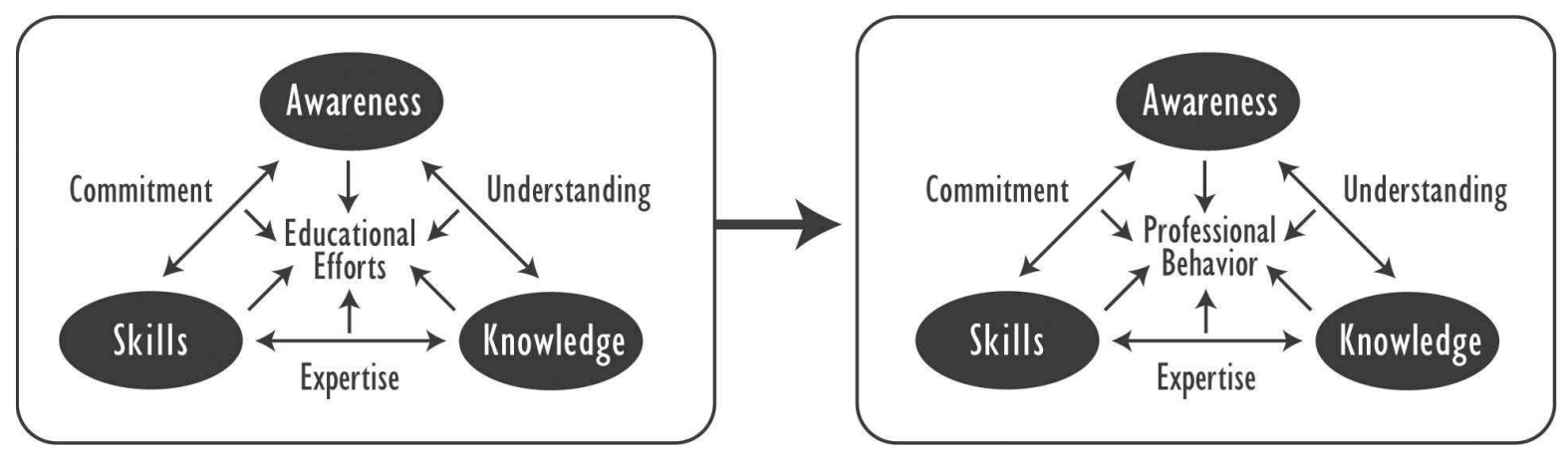

Figure 1. The humanistic model of professional education

educators are, the better their educational efforts will be. Improved educational efforts should then in turn focus on improving students' awareness, skills, and knowledge in order to allow them to engage in optimal professional behavior.

\section{Conclusions}

These findings should alert all dental and dental hygiene educators to the importance of educating their students as well as practicing professionals clearly, comprehensively, and consistently over time about infection control, along with the science and rationale supporting the recommended guidelines. Dental educators themselves need to be aware and knowledgeable about best practices, so they can educate their students to adapt and implement these best practices to protect themselves and their patients. Educating providers and students about the effectiveness of gloves for infection control should become a priority and needs to include at least information that there is a wide variation between the barrier control effectiveness of different glove types; that wearing protective gloves does not provide 100 percent protection and does not replace hand-washing as a critical means in the prevention of the transmission of communicable diseases; and that mechanical and chemical manipulations can compromise the integrity of gloves, which makes it important to change gloves more often during long and stressful procedures.

\section{REFERENCES}

1. Mosley JW, White E. Viral hepatitis as an occupational hazard of dentists. J Am Dent Assoc 1975;90:992-7.

2. Mosley JW, Edwards VM, Casey G, Redecker AG, White E. Hepatitis B virus infection in dentists. N Engl J Med 1975;293:729-34.

3. Feldman RE, Schiff ER. Hepatitis in dental professionals. JAMA 1975;232:1228-30.

4. Verrusio CA, Neidle EA, Nash DK, Silverman S Jr, Horowitz AM, Wagner KS. The dentist and infectious diseases: a national survey of attitudes and behavior. J Am Dent Assoc 1989;118:553-62.

5. Council on Dental Materials and Devices, Council on Dental Therapeutics. Infection control in the dental office. J Am Dent Assoc 1978;93:673-7.

6. Centers for Disease Control. Recommendations for prevention of HIV transmission in health care settings. MMWR Morb Mortal Wkly Rep 1987;36(Suppl):35185.

7. Centers for Disease Control. Guidelines for infection control in dental health care settings, 2003: recommendations and reports. Dec 19 2003/52 (RR17):1-61.

8. Huber MA, Terezhalmy GT. Adverse reactions to latex products: preventive and therapeutic strategies. J Contemp Dent Practice 2006;7(1):97-106.

9. Rego A, Roley L. In use barrier integrity of gloves: latex and nitrile superior to vinyl. Am J Infect Control 1999;27:405-10.

10. Korniewicz DM, Laughon BE, Cyr WH, Lytle CD, Larson E. Leakage of virus through used vinyl and latex examination gloves. J Clin Microbiol 1990;28:787-8.

11. Korniewicz DM, El-Masri M, Broyles JM, Martin $\mathrm{CD}$, O'Connell KP. Performance of latex and nonlatex medical gloves during simulated use. Am J Infect Control 2002;30(20):133-8. 
12. Kerr LN, Chaput MP, Cash LD, O'Malley LG, Sarhani EM, Teixera JC, et al. Assessment of the durability of medical examination gloves. J Occup Environ Hyg 2004;9(1):607-12.

13. Fischer M, Reddy VR, Williams FM, Lin KY, Thacker JG, Edlich RF. Biomechanical performance of powder-free examination gloves. J Emerg Med 1999;17(6):1011-8.

14. Patel H, Fleming GJ, Burke FJ. Puncture resistance and stiffness of nitrile and latex dental examination gloves. $\mathrm{Br}$ Dent J 2004;196:695-700.

15. Sawyer J, Bennett A. Comparing the level of dexterity offered by latex and nitrile safeskin gloves. Ann Occup Hyg 2005;50(3):289-96. Epub 2005 Dec 15.

16. Find the right fit [News]. Dent Today 2003;22(6):44

17. U.S. Food and Drug Administration, Center for Devices and Radiological Health. Personal protective equipment (PPE) and patient care. At: www.fda.gov/cdrh/ppe/gloves. html. Accessed: September 26, 2008.

18. Jordan SL, Stowers MF, Trawick EG, Theis AB. Glutaraldehyde permeation: choosing the proper glove. Am J Infect Control 1996;24:67-9.

19. Ready MA, Schuster GS, Wilson JT, Hanes CM. Effects of dental medicaments on examination glove permeability. J Prosthet Dent 1989;61:499-503.

20. Mellstrom GA, Lindberg M, Boman A. Permeation and destructive effects of disinfectants on protective gloves. Contact Dermatitis 1992;26:163-70.

21. Otis LL, Cottone JA. Prevalence of perforations in disposable latex gloves during routine dental treatment. J Am Dent Assoc 1989;118:321-4.

22. Albin MS, Bunegin L, Duke ES, Ritter RR, Page CP. Anatomy of defective barrier: sequential glove leak detection in a surgical and dental environment. Crit Care Med 1992;20:170-84.

23. Gerberding JL, Little C, Tarkington A, Brown A, Scheter WP. Risk of exposure of surgical personnel to patient's blood during surgery at San Francisco General Hospital. N Engl J Med 1990;322:1788-93.

24. Larsen EL. APIC guideline for hand washing and hand antisepsis in health care settings. Am J Infect Control 1995;23:251-69.

25. Olsen RJ, Lynch P, Coyle MB, Cummings J, Bokete T, Stamm WE. Examination gloves as barriers to hand contamination in clinical practice. JAMA 1993;270:350-3.
26. Nikawa H, Hamada T, Tamamoto M, Abekura H, Murata H. Perforation of dental gloves during prosthodontic treatments as assessed by conductivity and water inflation tests. Int J Prosthod 1996;9:362-6.

27. Merchant VA, Molinari JA, Pickett T. Microbial penetration of gloves following usage in routine dental procedures. Am J Dent 1992;5:95-6.

28. Avery CM, Hjort A, Walsh S, Johnson PA. Glove perforation during surgical extraction of wisdom teeth. Oral Surg Oral Med Oral Pathol Oral Radiol Endod 1998;86: 23-5.

29. Schwimmer A, Massoumi M, Barr CE. Efficacy of double gloving to prevent inner glove perforation during outpatient oral surgical procedures. J Am Dent Assoc 1994;125:196-8.

30. Gani JS, Anseline PF, Bisset RL. Efficacy of double versus single gloving in protecting the operating team. Aust N Z J Surg 1990;60:171-5.

31. Webb JM, Pentlow BD. Double gloving and surgical technique. Ann R Coll Surg Engl 1993;75:291-2.

32. Wilson SJ, Sellu D, Uy A, Jaffer MA. Subjective effects of double gloves on surgical performance. Ann R Coll Surg Engl 1996;78:20-2.

33. Kanjirath PP, Peters MC, Inglehart MR. Treating patients with herpes simplex virus infections: dental and dental hygiene students' knowledge, attitudes, and professional behavior. J Dent Educ 2007;71(9):1133-44.

34. Coplen A, Chapman J, Kanjirath P, Gu F, Fenno C, Peters M. Nitrile, latex, and vinyl gloves permeabiliy testing using serratia marcescens. Presentation at the Clinical Research Symposium on Clinical Research to Clinical Practice: Managing Challenges at the Cutting Edge, University of Michigan, September 11-13, 2008.

35. Higgins CR, Schofield JK, Tatnall FM, Leigh IM. Natural history, management, and complications of herpes labialis. J Med Virol 1993;1(Suppl):22-6.

36. Spruance SL, Overall JC, Kern ER, Krueger GG, Pliam V, Miller W. The natural history of recurrent herpes simplex labialis. N Engl J Med 1997;297:69-75.

37. Inglehart MR, Tedesco LA, Valachovic RW. Quality of life: refocusing dental education. Chapter 16. In: Inglehart MR, Bagramian RA, eds. Oral health and quality of life. Chicago: Quintessence Publishers, 2002:183-92. 